\title{
Ictal Psychosis under Disguise of Mania: How to Unravel
}

\author{
Abdelgadir H. Osman ${ }^{1 *}$, Sabah M. Alsharief ${ }^{2}$ \\ ${ }^{1}$ Psychiatric Department, Faculty of Medicine, University of Khartoum, Khartoum, Sudan \\ ${ }^{2}$ Psychiatric Training Scheme, Sudan Medical Council, Khartoum, Sudan \\ Email: ^abdelgadir1159@yahoo.com, *abdelgadir.osman@uofk.edu, alshryfsbah56@gmail.com
}

How to cite this paper: Osman, A.H. and Alsharief, S.M. (2020) Ictal Psychosis under Disguise of Mania: How to Unravel. Open Journal of Psychiatry, 10, 216-224.

https://doi.org/10.4236/ojpsych.2020.104018

Received: August 31, 2020

Accepted: October 17, 2020

Published: October 20, 2020

Copyright (c) 2020 by author(s) and Scientific Research Publishing Inc. This work is licensed under the Creative Commons Attribution International License (CC BY 4.0).

http://creativecommons.org/licenses/by/4.0/ cc (i) Open Access

\begin{abstract}
Background: Ictal psychosis without remarkable cognitive impairment is uncommon occurrence, presents diagnostic challenges to clinicians, often misdiagnosed as functional psychosis. Case Presentation: We present 3 cases of young adult men admitted to psychiatric ward as functional psychosis. They presented with irritability, physical aggression and mild cognitive impairment with intense emotional symptoms, and persecutory ideas and delusions. Two were wrongly diagnose as mania while the third was mimicking schizophrenia in its presentation. They received antipsychotic treatment and misdiagnosed as functional psychosis. They did not respond well to such treatment, until, series electroencephalograms were taken which revealed evidence of ictal psychosis. All, thence, responded well to addition of antiepileptic treatment. This, not only, proves to be effective, but also determined future management and prognosis. Conclusion: These cases shine light onto the role of the frontal cortex in the genesis of quasi-manic episodes and highlight the importance of EEG investigations in first episode of acute psychosis.
\end{abstract}

\section{Keywords}

Ictal Psychosis, Ictal Mania, Frontal Lobe Ictal Psychosis

\section{Background}

Many case report series and retrospective studies have been published addressing post-ictal psychosis and post-ictal mania, whether the epileptogenic foci origin are in the temporal or frontal lobe. However, few reports exist in the literature on mania during the inter-ictal period or not associated with motor fits originating in the frontal lobe. Three fundamental presentations of frontal lobe ictal and lesion abnormalities have been noted in different papers. 
1) Affective psychiatric presentation of frontal lobe dysfunction (FLD)

Most of the subjects in these studies had known or suspected of psychiatric disorders potentially contributing to alterations in prefrontal function. Studies using Positrons Emission Tomography (PET) scan have documented focal decreases in frontal cortical activity associated with various neuropsychiatric disorders, as well as transient mental states, such as induced sadness and episodes of mood disorder [1] [2] [3]. The reported reductions in prefrontal size or activity may, therefore, represent a predisposition to affective states relevant to aggressive behaviour, without necessarily signifying an incapacity to avoid actual violent acts [4] [5] [6].

Persons who have clinically evident neuropsychiatric disorders involving focal injury to structural or functional components of the frontal network, particularly the orbital and ventromedial prefrontal cortex, comprise a different group. Retrospective data strongly support a link between the disinhibited type of frontal network syndrome and aggressive bouts with lack of control. Case descriptions suggest that focal orbitofrontal injury specifically impairs the capacity for social judgment, risk avoidance and lack of empathy, which leads to inappropriate aggression. The actual frequency of violent behaviour, however, seems relatively low. Based on the results reviewed here, a reasonable speculation for the increased risk of violence associated with clinically significant focal frontal lobe injury might be $10 \%$ over the base rate for a given population. Confirmation of this estimate must await prospective studies [6] [7] [8].

In addition to using prospective design, future studies testing the relationship between frontal lobe dysfunction and aggression should incorporate controls for known risk factors contributing to violent behaviour. Clinical descriptions of the nature and extent of frontal lobe impairments, coupled with attention to the type (premeditated versus impulsive), frequency and severity of aggressive behaviour, and victims characteristics should help to clarify the brain-behaviour relationships involved [9] [10].

2) Aggression due to frontal lobe ictal activity

The Vietnam Head Injury Study (VHIS) found that subjects with lesions limited to the frontal lobes tended to show more aggressive and violent behaviours compared with patients with non-frontal head injury and controls without head injury. About $14 \%$ of subjects with frontal lobe injury engaged in fights or damaged property, compared with about $4 \%$ of controls without head injury. The study also found a significant association between increased aggression and focal medio-frontal and orbitofrontal injury identified on brain computerized Tomography (CT) scan. Reports have also found higher rates of antisocial behaviour, including stealing, physical assault and sexual comments or advances [11] [12] [13] in patients with front otemporal dementia, even when compared with equally cognitively impaired patients with Alzheimer's disease.

Overall, these neuropsychological studies tend to support a significant association between prefrontal executive dysfunction measured by neuropsychological testing and increased antisocial and aggressive behaviour. In populations with a 
prior risk of antisocial behaviour or aggression, the presence of executive function deficits may have value in assessing the future likelihood of aggression [14] [15] [16].

3) Cognitive and personality changes (FLD)

In one of the first documented cases of emotional disorder due to a brain lesion, Phineas Gage famously suffered from accidental damage to the frontal lobe in 1848. The iron bar that forced its way through his cranium caused lesions in the left and right ventromedial regions of the prefrontal cortex [17] [18] [19]. Mr. Gage, who was an exemplary citizen before the accident, afterwards became a completely different person-impatient, rude and prone to outbursts of anger and rage. It was proposed that personality changes after frontal lobe damage could be classified under "pseudo-psychopathy" or "pseudo-depression". Pseudo-depression is more frequently associated with lesions in the left frontal lobe and is characterised by apathy, loss of initiative, low mood and reduced sexual interest. Several lesion studies have demonstrated that damage to left frontal areas contribute specifically to depressive syndromes, whereas the consequences of right prefrontal lobe damage are less clear and may be associated with pseudo-psychopathic behaviour or mania [20] [21]. Although the lateralisation effect has not been found in all studies, the association between mood disturbances and prefrontal lesions is widely recognised [22] [23].

Overall, these neuropsychological studies tend to support a significant association between prefrontal executive dysfunction measured by neuropsychological testing and increased antisocial and aggressive behaviour. In populations with a prior risk of antisocial behaviour or aggression, the presence of executive function deficits may have value in assessing the future likelihood of aggression [24] [25].

The objective of this article therefore to improve diagnosis of ictal psychosis and give clinical examples of how elusive this can be in clinical settings.

\section{Case Presentation}

\section{Case 1}

Mr. A is 20-year-old man from Omdurman, Sudan. Mr. A has neither previous history of psychiatric illness nor any positive family history pertaining to psychiatric illness.

Mr. A's personal history was unremarkable; he left school at the age of 13 to join a family business. Shortly before his admission, he was running his family's local shop.

Mr. A. was brought to Eltigany Elmahy psychiatric hospital presenting with a three-month history of changes in behaviour, becoming disinhibited, undressing himself in public arias, over-talkative and hyperactive with an irritable mood. $\mathrm{He}$ was angry and aggressive towards his family members, construing their overprotective attitudes towards him in a persecutory manner. He was muddled, unable to answer questions pertaining to date and time and did not cooperate with questions relating to memory and general information. 
He absconded several times from the family home. He eventually succumbed to family pressure and was seen at the medical casualty ward for an investigation. All his blood tests were normal. He tested negative for malaria, typhoid and paratyphoid. He was then advised to be admitted for further treatment and investigation, but his family took him home with prescriptions for olanzapine and sodium valproate, which were not used.

Mr. A. was brought back to hospital six weeks later due to an escalation in his aggressive behaviour. He had become over vigilant and suspicious. A CT scan of the brain revealed no abnormality. He was given repeated intramuscular injections of haloperidol and promethazine during his second hospital in-patient stay.

On the second week, he became less aggressive and paranoid, but continued to lack insight and awareness of time and date, with rather patchy recollection of recent events. Electroencephalogram (EEG) results in the second week revealed spikes and delta waves in the frontal brain montage. The sodium valproate dose was increased to $1000 \mathrm{mg}$ per day following the EEG, and the olanzapine dose was brought down to $5 \mathrm{mg}$ per day. Mr. A improved remarkably and became lucid, cooperative and calm by the end of the second week.

Another EEG performed in the fourth week revealed the disappearance of delta waves and spikes in the EEG montage. Magnetic resonance imaging showed no structural abnormality. Mr. A was discharged and followed up at the outpatient one month later. He was deemed to be in good health with a stable mental state.

\section{Case 2}

Mr. Y is 14-year-old Libyan student, single, in his third year of high school with moderate school performance. He is the second eldest of four siblings. His father is a labourer, and his mother is a teacher. There was no family history of mental illness. The pre-morbid personality was described as religious, sociable, with a good attitude toward others. Mr. Y had no previous history of substance abuse or forensic history.

Mr. Y was brought by his father to our mental health unit at Eltigany Elmahy teaching hospital with very aggressive behaviour. The case history started 18 months prior to admission in his country of Libya when he started crying and laughing alone; he also became verbally aggressive.

His condition had deteriorated three months prior to his admission to Eltigany Elmahy hospital. He was exhibiting physical aggression towards his father and other family members. This was the last straw that forced his father to take him to hospital. It was reported that there were periods in the 12 months prior to admission when the patient seemed almost normal for at least three weeks.

Although Mr. Y had had no past psychiatric history, nonetheless, he had seen doctors in Libya and was admitted for a couple of weeks in a psychiatric unit in Tunisia. He underwent an intensive investigation including magnetic resonance imaging (MRI) scan, but apparently no EEG was carried out.

Mania was diagnosed and prescribed olanzapine and benzodiazepines. Mr. Y's 
symptoms showed a period of improvement that did not last more than three weeks, and he was then brought to Sudan for further help. Initially, Mr. Y was taken to see local healers as he did not find solace from medical experts.

Mr. Y was of average height and weight, and appeared physically healthy. All physical checks and system examinations revealed no abnormality. He was both verbally and physically aggressive. He continued to display an irritable mood, shouted and spoke in a high tone and volume. Otherwise, he was not cooperative for cognitive testing, but was clinically lucid and aware of his surroundings.

Regarding the management process, the patient was admitted to the psychiatric ward. The full blood count, renal function tests, liver function tests, thyroid function tests and urine analysis all were normal. In hospital, the patient was treated with an injectable antipsychotic and diazepam for three days with no improvement. He received two sessions of electro-convulsive therapy (ECT), after which he became calm.

Further investigations were ordered. EEG showed occipital traces, predominated by alpha waves, whilst frontal traces were predominantly composed of delta waves, and some spike waves were detected. MRI did not show any structural abnormality. A diagnosis of frontal lobe epilepsy was made.

Treatment alterations meant low dose oral olanzapine $(5 \mathrm{mg})$ twice a day, which was later reduced to once a day. However, remarkable improvement was achieved with the addition of sodium valproate $200 \mathrm{mg}$ twice a day, which was later increased to $800 \mathrm{mg}$ day. During admission, the patient was comparatively calm and friendly with his family and others. Within 7 days, the patient improved and returned back to normal and was discharged in good condition to complete his treatment at home.

Six months later, the patient remained well and was taken off olanzapine, but remained on $400 \mathrm{mg}$ sodium valproate daily. His father continued to give our unit feedback of the status of his son who has returned to his education.

Case 3

Mr. M is a 29-year-old engineer who graduated from Khartoum University. He grew up in Saudi Arabia, and his parents still work and live there. He is the third of six siblings. His eldest sister is married and lives in Sudan, with whom he is residing, together with two other brothers in a family villa with domestic helpers whilst the elder sister runs the daily affairs. Mr. M had a happy and unremarkable upbringing with many friends. He was socially active and a high achiever academically.

Mr. M presented with a six-month history of recurrent bouts of paranoid psychosis concerning government agents that monitor his life, believing that secret agents suspected that he was affiliated with the opposition party. Mr. M believes that these secret agents are able to manipulate him by adding, blocking and taking away some of his thoughts. He hears them discussing him in the third person. He was very distressed over his experience. Moreover, he started to believe that his brother had started to act funny, making derogatory comments about him and perhaps had started colluding with the secret agents. Mr. M held 
strong beliefs that he was monitored by secret agents and did not appear to have any serious depressive component, though he appeared bewildered. He had no other cognitive impairments.

The family reported increasing tension between the patient and the elder brother. Mr. M gave up his engineering job that he had started a year earlier with a local telecommunication company and went to have a break with his parents in Saudi Arabia for couple of months, where he reported that his distress had subsided. He returned to Sudan a month prior to his consultation, when his psychosis flared up again.

Following his consultation, he was started on a low dose of risperidone $(2 \mathrm{mg}$ twice a day), after initial investigations revealed no physical abnormality. Tests included full blood counts, liver function tests, urea and electrolyte levels, thyroid function tests and blood sugar levels. A week later, an EEG was performed, which revealed spike waves and delta waves in the temporal tracing of the brain. MRI results showed no brain abnormalities.

Carbamazepine was added to his treatment, which proved to be effective three days after commencement. All his delusions and hallucinations disappeared by the seventh day on carbamazepine. Three weeks later, Mr. M was back at work.

\section{Discussion}

Although bipolar/manic depressive relapses in a patient with past history of similar episodes is easily assumed and treated along the conventional psychotropic and other methods. However, for first episode psychosis with manic features it's important to rule out non-functional causes including ictal psychosis. Increasing reports in the literature recognise the importance of recurrent EEG investigations to enable clear diagnoses of manic depressive disorder, differentiated from disorders of ictal frontal or temporal brain abnormalities [14] [15] [23]. In comparison with ictal mania post ictal mania seems to simulate functional mania in all phenomenology with elated mood grandiose delusion and religiosity in absence of cognitive impairment, however, in most cases this preceded by ictal motor activity to herald the start of the post ictal mania [23] [24] [25]. The importance of electrophysiological investigations is greater in young patients below the age of 20 years, especially if they lack a strong family history of bipolar disorder. The presence of visual and olfactory perceptual disturbances increase suspicion towards an organic brain pathology, yet this is not always easily recognised and be confounded with bipolar clinical symptoms [24] [25].

The lesson learnt from these cases, therefore, to prudently recommend, electrophysiological study for all inception attacks of mania or psychosis in absence of strong family history of similar condition.

\section{Conclusion}

These cases highlight the importance of clinical investigations into cases of bipolar mania, especially in subjects who present with cognitive problems asso- 
ciated with perceptual abnormalities and in young patients below 20 years of age. Moreover, in the clinical picture, one may be able to pick up subtle differences, such as cognitive derangement during the clinical presentation and the speed in the build-up of symptoms, as this peaks rapidly in cases of ictal abnormality; however, this is not always the case. Early diagnosis of ictal psychosis does not only mean a different course of management, but also a different prognosis.

\section{Ethics Approval and Consent to Participate}

Informed written consent obtained from patients/(from parent for the minor) and hospital authority.

\section{Consent for Publication}

The study was reviewed and approved by Khartoum Medical School's ethics committee. As, this case report has not divulged any patients information, the Ethics Committee has given the authors the full consent for publication.

\section{Availability of Data and Material}

The datasets used during the current study available from the corresponding author on reasonable request.

\section{Conflicts of Interest}

All authors declare that they have no competing interests.

\section{Authors' Contributions}

Both $\mathrm{AO}$, and SA, carried out the project design, data collection, and drafting of manuscript. Both authors have been involved in reviewing and editing the manuscript, read and approved the final draft.

\section{References}

[1] Blumberg, H.P., Stern, E., Ricketts, S., et al. (1999) Rostral and Orbital Prefrontal Cortex Dysfunction in the Manic State of Bipolar Disorder. The American Journal of Psychiatry, 156, 1986-1988.

[2] Cavanagh, J.T.O., van Beck, M., Muir, W., et al. (2002) Case-Control Study of Neurocognitive Function in Euthymic Patients with Bipolar Disorder: An Association with Mania. British Journal of Psychiatry, 180, 320-326.

https://doi.org/10.1192/bjp.180.4.320

[3] Kinney, M.O. and Kaplan, P.W. (2017) An Update on the Recognition and Treatment of Non-Convulsive Status Epilepticus in the Intensive Care Unit. Expert Review of Neurotherapeutics, 17, 987-1002. https://doi.org/10.1080/14737175.2017.1369880

[4] Filley, C.M., Price, B.H., Nell, V., et al. (2001) Toward an Understanding of Violence: Neurobehavioral Aspects of Unwarranted Physical Aggression. Neuropsychiatry, Neuropsychology \& Behavioral Neurology, 14, 1-4. 
[5] Meyers, C.A., Berman, S.A., Scheibel, R.S., et al. (1992) Case Report: Acquired Antisocial Personality Disorder with Unilateral Left Orbital Frontal Lobe Damage. Journal of Psychiatry \& Neuroscience, 17, 121-125.

[6] Grafman, W.D., et al. (1996) Frontal Lobe Injuries, Violence and Aggression: A Report of the Vietnam Head Injury Study. Neurology, 46, 1231-1238. https://doi.org/10.1212/WNL.46.5.1231

[7] Monji, A., Yanagimoto, K., Maekawa, T., Sumida, Y., Yamazaki, K. and Kojima, K. (2005) Plasma Folate and Homocysteine Levels May Be Related to Interictal "Schizophrenia-Like" Psychosis in Patients with Epilepsy. Journal of Clinical Psychopharmacology, 25, 3-5. https://doi.org/10.1097/01.jcp.0000150225.76748.73

[8] Toffol, B. and Kanemoto, K. (2016) Postictal Psychoses: Clinical and Neurobiological Findings. Encephale, 42, 443-447. (In French) https://www.ncbi.nlm.nih.gov/pubmed/27198074 https://doi.org/10.1016/j.encep.2015.12.023

[9] Nishida, T., Kudo, T., Inoue, Y., et al. (2006) Postictal Mania versus Postictal Psychosis: Differences in Clinical Features, Epileptogenic Zone, and Brain Functional Changes during Postictal Period. Epilepsia, 47, 2104-2114.

https://www.ncbi.nlm.nih.gov/pubmed/17201710 https://doi.org/10.1111/j.1528-1167.2006.00893.x

[10] Chaudhury, S., Rohatgi, S., Murthy, P.S., Soren, S., Bakhla, A.K. and Kiran, C. (2015) A Clinical Study of Postictal Psychoses. Saudi Journal for Health Sciences, 4, 99-103. https://doi.org/10.4103/2278-0521.157873

[11] Kudo, T., Ishida, S., Kubota, H. and Yagi, K. (2001) Manic Episode in Epilepsy and Bipolar I Disorder: A Comparative Analysis of 13 Patients. Epilepsia, 42, 1036-1042. https://doi.org/10.1046/j.1528-1157.2001.0420081036.x

[12] Fogang, Y., Legros, B., Depondt, C., et al. (2017) Yield of Repeated Intermittent EEG for Seizure Detection in Critically Ill Adults. Neurophysiologie Clinique, 47, 5-12. https://doi.org/10.1016/j.neucli.2016.09.001

[13] Fong, G.C., Ho, W.Y., Tsoi, T.H., Fong, K.Y. and Ho, S.L. (2002) Lateral Temporal Hyperperfusion in Postictal Psychosis Assessed by 99mTc-HMPAO SPECT. Neuroimage, 17, 1634-1637. https://doi.org/10.1006/nimg.2002.1292

[14] Boylan, L.S. (2001) Postictal Psychosis Related Regional Cerebral Hyperfusion. Journal of Neurology, Neurosurgery, and Psychiatry, 70, 137-138. https://doi.org/10.1136/jnnp.70.1.137a

[15] Lancman, M.E.C.W., Asconapé, J.J. and Penry, J.K. (1994) Clinical Management of Recurrent Postictal Psychosis. Journal of Epilepsy, 7, 47-51. https://doi.org/10.1016/0896-6974(94)90120-1

[16] Osman Abdelgadir, H., Sabah, E. and Hassabarassol, S. (2020) Functional Neurological Disorder: Characteristics and Outcome in a Limited-Resources Country (Sudan). Epilepsy \& Behavior, 111, 107151. https://doi.org/10.1016/j.yebeh.2020.107151

[17] Heckers, S. (2001) Neuroimaging Studies of the Hippocampus in Schizophrenia. Hippocampus, 11, 520-528. https://doi.org/10.1002/hipo.1068

[18] Struck, A.F., Osman, G., Rampal, N., et al. (2017) Time-Dependent Risk of Seizures in Critically Ill Patients on Continuous Electroencephalogram. Annals of Neurology, 82, 177-185. https://doi.org/10.1002/ana.24985

[19] Clancy, M.J., Clarke, M.C., Connor, D.J., et al. (2014) The Prevalence of Psychosis in Epilepsy; a Systematic Review and Meta-Analysis. BMC Psychiatry, 14, Article No. 75. https://doi.org/10.1186/1471-244X-14-75 
[20] Irwin, L.G. and Fortune, D.G. (2014) Risk Factors for Psychosis Secondary to Temporal Lobe Epilepsy: A Systematic Review. The Journal of Neuropsychiatry and Clinical Neurosciences, 26, 5-23. https://doi.org/10.1176/appi.neuropsych.12120403

[21] Kanemoto, K., Tadokoro, Y. and Oshima, T. (2012) Psychotic Illness in Patients with Epilepsy. Therapeutic Advances in Neurological Disorders, 5, 321-334. https://doi.org/10.1177/1756285612454180

[22] Devinsky, O., Abramson, H., Alper, K., FitzGerald, L.S., Perrine, K., Calderon, J. and Luciano, D. (1995) Postictal Psychosis: A Case Control Series of 20 Patients and 150 Controls. Epilepsy Research, 20, 247-253. https://doi.org/10.1016/0920-1211(94)00085-B

[23] Liu, H.C., Chen, C.H., Yeh, I.J. and Sung, S.M. (2001) Characteristics of Postictal Psychosis in a Psychiatric Center. Psychiatry and Clinical Neurosciences, 55, 635639. https://doi.org/10.1046/j.1440-1819.2001.00917.x

[24] Leutmezer, F., Podreka, I., Asenbaum, S., Pietrzyk, U., Lucht, H., Back, C., Benda, N. and Baumgartner, C. (2003) Postictal Psychosis in Temporal Lobe Epilepsy. Epilepsia, 44, 582-590. https://doi.org/10.1046/j.1528-1157.2003.32802.x

[25] Fong, G.C., Fong, K.Y., Mak, W., Tsang, K.L., Chan, K.H., Cheung, R.T. and Ho, S.L. (2000) Postictal Psychosis Related Regional Cerebral Hyperfusion. Journal of Neurology, Neurosurgery, and Psychiatry, 68, 100-101.

https://doi.org/10.1136/jnnp.68.1.100

\section{Abbreviations}

$\mathrm{EEG}=$ Electroencephalogram;

FLD $=$ Frontal Lobe Dysfunction;

PET = Positrons Emission Tomography;

$\mathrm{CT}$ = Computed Tomography;

VHIS $=$ Vietnam Head Injury Study. 